\title{
Functional Contribution of Adult-Generated Olfactory Bulb Interneurons: Odor Discrimination versus Odor Memory
}

\author{
Katherine G. Akers, ${ }^{1}$ Masanori Sakaguchi, ${ }^{1}$ and Maithe Arruda-Carvalho ${ }^{1,2}$ \\ ${ }^{1}$ Neurosciences and Mental Health, The Hospital for Sick Children, Toronto, Ontario M5G 1X8, Canada, and ${ }^{2}$ Institute of Medical Science, University of \\ Toronto, Toronto, Ontario M5S 1A8, Canada \\ Review of Breton-Provencher et al.
}

Processing olfactory information is critical for an animal's ability to locate food, detect danger, recognize conspecifics, find mates, and rear offspring. The olfactory bulb $(\mathrm{OB})$ is the initial site of olfactory information processing in the brain. Within the OB, mitral cells receive input from sensory neurons in the olfactory epithelium and send output to higher-order structures such as the piriform cortex. Mitral cell activity is tightly regulated by dendrodendritic synapses with two types of local inhibitory interneurons: granule and periglomerular cells. Interestingly, $\mathrm{OB}$ granule and periglomerular cells differ from most neurons in that their production continues well beyond embryogenesis and into adulthood, prompting the question of whether adult-generated $\mathrm{OB}$ interneurons make a unique contribution to $\mathrm{OB}$ function.

In a recent article in The Journal of Neuroscience, Breton-Provencher et al. (2009) examined the impact of reducing adult neurogenesis on $\mathrm{OB}$ function. They decreased neurogenesis by infusing cytosine arabinoside (AraC) via osmotic

Received Jan. 26, 2010; revised Feb. 18, 2010; accepted Feb. 22, 2010.

K.G.A. is supported by a postdoctoral fellowship from the Ontario Ministry of Research and Innovation. M.S. is supported by Japanese Society for the Promotion of Science Postdoctoral Fellow for Research Abroad. M.A.-C. is supported by a Restracomp Award from The Hospital for Sick Children.

Correspondence should be addressed to Katherine G. Akers, Neurosciences and Mental Health, The Hospital for Sick Children, 555 University Avenue, 6020 McMaster Building, Toronto, 0N M5G 1X8, Canada. E-mail: katherine.akers@sickkids.ca.

D0I:10.1523/JNEUROSCI.0443-10.2010

Copyright $\odot 2010$ the authors $\quad 0270-6474 / 10 / 304523-03 \$ 15.00 / 0$ minipump into the lateral ventricle of mice for $28 \mathrm{~d}$. AraC is an antimitotic drug that incorporates into the DNA of dividing cells and induces apoptotic cell death, thereby disrupting the proliferation of neural progenitor cells in the subventricular zone and their subsequent migration to the OB. After infusion, mice treated with AraC exhibited a 75\% reduction in the number of $\mathrm{OB}$ cells expressing doublecortin, a marker for immature neurons, compared with control mice treated with saline.

Breton-Provencher et al. (2009) found that although the reduction of adult neurogenesis left the basic structure of the OB intact, it had significant consequences for $\mathrm{OB}$ network function. Single-cell recordings revealed that mitral cells from AraC-treated mice exhibited less frequent spontaneous IPSCs and smaller evoked dendrodendritic inhibitory currents compared with control mice, indicating that reduction of neurogenesis decreased mitral cell inhibition. This decreased inhibition was not due to intrinsic changes in the electrophysiological properties of mitral cells, which displayed normal postsynaptic $\mathrm{GABA}_{\mathrm{A}}$ receptor function as well as normal passive membrane properties and spontaneous firing activity. Rather, the decreased inhibition appeared to result from fewer inhibitory synapses made onto the mitral cells, as the lateral dendrites of mitral cells from AraC-treated mice had fewer sites immunopositive for gephryn, a postsyn- aptic $\mathrm{GABA}_{\mathrm{A}}$ receptor scaffolding protein. Because the lateral dendrites are where granule cells form inhibitory contacts, this finding suggests that the decrease in mitral cell inhibition resulted from fewer granuleto-mitral cell synapses. As dendrodendritic interactions between granule and mitral cells are largely responsible for driving gamma frequency oscillations (Lagier et al., 2004), the authors predicted that AraCtreated mice would have alterations in this type of oscillatory activity. Indeed, local field potential recordings revealed that AraCtreated mice showed a reduction in the peak frequency of gamma frequency oscillations measured from the mitral cell layer after stimulation of the olfactory nerve $(\sim 45 \mathrm{~Hz}$ in saline-treated mice vs $\sim 39 \mathrm{~Hz}$ in AraCtreated mice).

These findings suggest that adult-generated $\mathrm{OB}$ interneurons are critical for shaping the overall pattern of OB network activity and, therefore, may make an important contribution to olfactory-associated behavior. In particular, OB interneurons may play a role in perceptual discrimination between odors. Because each granule cell forms dendrodendritic contacts with multiple mitral cells, the excitation of a granule cell by a mitral cell leads to the inhibition of neighboring mitral cells. This process of lateral inhibition may sharpen the distinction between neural representations of similar odors and thereby facilitate odor discrimination. For example, in the rabbit, individual mitral cells showing excitatory responses to certain odorants showed inhib- 
Table 1. Impairment in olfactory-associated behavior after reduction of adult $\mathrm{OB}$ neurogenesis

\begin{tabular}{|c|c|c|c|c|c|}
\hline Study & Method of reducing $O B$ neurogenesis & $\begin{array}{l}\text { Impact on immature } \\
\text { adult-generated neurons }\end{array}$ & $\begin{array}{l}\text { Impact on mature adult-generated } \\
\text { neurons }\end{array}$ & $\begin{array}{l}\text { Odor } \\
\text { discrimination }\end{array}$ & Odor memory \\
\hline Gheusi et al., 2000 & $\mathrm{NCAM}^{-1-}$ & Migration in RMS: impaired & GCL width: $35 \%$ reduction & Impaired & $\begin{array}{l}\text { Impaired short-term } \\
\text { (80-100 min) }\end{array}$ \\
\hline Enwere et al., 2004 & Aging, Lifr ${ }^{+/-}, \mathrm{TGF} \alpha^{\text {wa1/wa1 }}$ & $\begin{array}{l}\text { BrdU }+/ \text { Calretinin }+ \text { cells ( } 4 \text { wk } \\
\text { postinjection): } 59 \% \text { reduction } \\
\text { in GL in aged mice }\end{array}$ & $\begin{array}{l}\text { BrdU }+/ G A B A+\text { cells ( } 4 \text { wk postinjection): } \\
41 \% \text { reduction in } \mathrm{GL}, 55 \% \text { reduction } \\
\text { in } \mathrm{GCL} \text { in aged mice }\end{array}$ & Impaired & \\
\hline Bath et al., 2008 & $\mathrm{BDNF}^{+/-}, \mathrm{TrkB}^{+/-}, \mathrm{BDNF}^{\text {Met/Met }}$ & Proliferation: no change & $\begin{array}{l}\text { BrdU + cells in GCL ( } 4 \text { wk postinjection): } \\
30 \% \text { reduction }\end{array}$ & Impaired & \\
\hline Imayoshi et al., 2008 & Nestin-CRE-ER ${ }^{\text {T2 }} \times$ NSE-DTA & DCX + cells in RMS: reduced & NeuN + cells in GCL: $10 \%$ reduction & No deficit & No deficit \\
\hline Lazarini et al., 2009 & Focal SVZ irradiation & $\begin{array}{l}\mathrm{DCX}+\text { cells in } \mathrm{GL} \text { and } \mathrm{GCL}: \\
70 \% \text { reduction }\end{array}$ & & No deficit & $\begin{array}{l}\text { Impaired long-term } \\
\text { (30 d) }\end{array}$ \\
\hline $\begin{array}{l}\text { Breton-Provencher } \\
\text { et al., } 2009\end{array}$ & LV AraC infusion & $\begin{array}{c}\mathrm{DCX}+\text { cells in } \mathrm{GCL}: \\
75 \% \text { reduction }\end{array}$ & NeuN+ cells in GCL: no change & No deficit & $\begin{array}{l}\text { Impaired short-term } \\
\quad(60-120 \mathrm{~min})\end{array}$ \\
\hline
\end{tabular}

BrdU, Bromodeoxyuridine; CRE, cAMP response element; GCL, granule cell layer; GL, glomerular layer; LV, lateral ventricle; RMS, rostral migratory stream; SVZ, subventricular zone.

itory responses to odorants with similar molecular structures, and this odor-specific response pattern was eliminated by blockade of inhibitory neurotransmission (Yokoi et al., 1995). Synchronous oscillatory activity in the OB may also be important for odor discrimination. In the honeybee, pharmacological desynchronization of odor-evoked oscillations impaired perceptual discrimination between structurally similar odorants (Stopfer et al., 1997).

Given that reduced neurogenesis leads to decreased mitral cell inhibition and altered $\mathrm{OB}$ oscillatory activity, mice with reduced adult $\mathrm{OB}$ neurogenesis might be expected to exhibit poor discrimination between odors. Surprisingly, Breton-Provencher et al. (2009) found that AraC-treated mice displayed normal odor discrimination but showed poor odor memory. Like control mice, AraC-treated mice showed a decrease in investigative behavior on repeated presentations of one odor (i.e., habituation) and an increase in investigative behavior on presentation of a second odor (i.e., dishabituation), indicating that they perceived the two odors as being different. When the delay between repeated presentations of the same odor was lengthened from 30 to 60 min, however, AraC-treated mice failed to habituate, suggesting that they could not remember an odor for $>30 \mathrm{~min}$. These findings, therefore, implicate adult-generated $\mathrm{OB}$ interneurons in memory for odors but not perceptual discrimination between odors.

A perplexing finding is that although AraC-treated mice showed no evidence of memory for a previously encountered odor after $60 \mathrm{~min}$, they were able to remember an association between an odor and a food reward for at least $7 \mathrm{~d}$. If mice cannot recognize an odor after a short span of time, it is difficult to understand how they could form long-term odor associations. One possible reason for this discrepancy is that short- and long-term odor memories were assessed by two different behavioral tasks, the former involving odor habituation and the latter involving odor-food associations, which may have differential requirements for adult-generated $\mathrm{OB}$ interneurons. For instance, odor-food associative memory might be unaffected by reductions in adult $\mathrm{OB}$ neurogenesis because associations between odors and nonolfactory stimuli rely on piriform and orbitofrontal cortices (Wilson et al., 2006) more than the OB.

This study is the latest in a growing collection of studies investigating the impact of reducing adult $\mathrm{OB}$ neurogenesis on olfactory-associated behavior in mice (Table 1). These studies, however, appear to provide conflicting results. Whereas some report that reduced neurogenesis impairs odor discrimination (Gheusi et al., 2000; Enwere et al., 2004; Bath et al., 2008), others report that reduced neurogenesis leaves odor discrimination intact but impairs odor memory (Breton-Provencher et al., 2009; Lazarini et al., 2009), and yet another reports that reduced neurogenesis impairs neither odor discrimination nor odor memory (Imayoshi et al., 2008).

One factor that may influence whether reduced $\mathrm{OB}$ neurogenesis impairs odor discrimination may be the difficulty of the discrimination. As noted by BretonProvencher et al. (2009), adult-generated $\mathrm{OB}$ interneurons may be exclusively involved in discrimination between highly similar odors (e.g., odors with similar molecular structures or similarly comprised mixtures of odors). For instance, aged or mutant mice with reduced $\mathrm{OB}$ neurogenesis discriminated between two distinct odors (100\% almond vs $100 \%$ coconut) but not two similarly comprised mixtures of the odors $(58 \%$ almond $/ 42 \%$ coconut vs $42 \%$ almond $/ 58 \%$ coconut) (Enwere et al., 2004). Perhaps some studies (Imayoshi et al., 2008; Breton-Provencher et al., 2009) did not find deficits in odor discrimination because the odors were too distinct, leaving open the possibility that using more similar odors could reveal impairments. A recent study (Lazarini et al., 2009), however, demonstrated that irradiated mice with reduced $\mathrm{OB}$ neurogenesis showed normal odor discrimination despite being extensively tested in tasks with highly similar odors, providing evidence that adult $\mathrm{OB}$ neurogenesis is not necessary for even the most difficult odor discriminations.

A second factor that might influence whether reduced $\mathrm{OB}$ neurogenesis impairs odor discrimination is the developmental timing of the experimental manipulation. As proposed by Lazarini et al. (2009), impairments in odor discrimination may be observed when $\mathrm{OB}$ neurogenesis is disrupted during embryogenesis but not during adulthood. That is, the ability to discriminate between odors may depend on the initial formation of $\mathrm{OB}$ neural circuitry brought about by the early wave of neurogenesis during the prenatal and early postnatal periods, but may not depend on the continued addition of new neurons to that circuitry during adulthood. Consistent with this idea, odor discrimination was impaired by genetic mutations that likely affected OB neurogenesis throughout development (Gheusi et al., 2000; Enwere et al., 2004; Bath et al., 2008) but was not impaired by manipulations that targeted neurogenesis specifically during adulthood (Imayoshi et al., 2008; Breton-Provencher et al., 2009; Lazarini et al., 2009). Furthermore, Enwere et al. (2004) found that a declining rate of neurogenesis in aged mice was associated with poor odor discrimination, suggesting that impairments in odor discrimination may emerge when $\mathrm{OB}$ circuitry breaks down during senescence. 
A third factor that may influence the type of behavioral impairment observed after reduction of $\mathrm{OB}$ neurogenesis is the age of the affected neurons. After their generation in the subventricular zone, newborn neurons destined for the OB undergo several migrational and maturational stages before fully integrating into $\mathrm{OB}$ circuitry. In the study by BretonProvencher et al. (2009), AraC-treated mice possessed the same number of mature $\mathrm{OB}$ granule cells as control mice yet exhibited alterations in OB network function and odor memory, suggesting that immature granule cells play a special role in OB function. In support of this possibility, immature adult-generated granule cells display greater immediate early gene expression in response to novel odors compared with mature cells (Magavi et al., 2005), and only immature adult-generated granule cells exhibit long-term potentiation of synaptic strength (Nissant et al., 2009). To determine how different ages of adult-generated $\mathrm{OB}$ interneurons might differentially contribute to olfactoryassociated behavior, it will be critical to target the cells at specific maturational stages.

The study by Breton-Provencher et al. (2009) is valuable in that it uses a multilevel approach from cell to behavior to demonstrate the importance of adult neurogenesis in olfactory information processing. Their finding of impaired odor memory after reduction of adult neurogenesis invites future studies to focus on precisely how adult-generated $\mathrm{OB}$ interneurons are involved in the retention of odor memories. Furthermore, as a complement to studies showing that reduction of $\mathrm{OB}$ neurogenesis impairs olfactory function, future studies could examine whether enhancement of $\mathrm{OB}$ neurogenesis improves olfactory function. Such studies would increase our understanding of how new neurons can be successfully integrated into existing neural circuits, which could propel efforts to improve functional recovery from brain injury or disease. A comprehensive knowledge of how brain pathology and/or the recovery of brain function might involve adult neurogenesis in the $\mathrm{OB}$, hippocampus, and neocortex will be fundamental for the translation of basic research findings to clinically relevant situations.

\section{References}

Bath KG, Mandairon N, Jing D, Rajagopal R, Kapoor R, Chen ZY, Khan T, Proenca CC, Kraemer R, Cleland TA, Hempstead BL, Chao MV, Lee FS (2008) Variant brain-derived neurotrophic factor (Val66Met) alters adult olfactory bulb neurogenesis and spontaneous olfactory discrimination. J Neurosci 28:23832393.

Breton-Provencher V, Lemasson M, Peralta MR 3rd, Saghatelyan A (2009) Interneurons produced in adulthood are required for the normal functioning of the olfactory bulb network and for the execution of selected olfactory behaviors. J Neurosci 29:15245-15257.

Enwere E, Shingo T, Gregg C, Fujikawa H, Ohta S, Weiss S (2004) Aging results in reduced epidermal growth factor receptor signaling, diminished olfactory neurogenesis, and deficits in fine olfactory discrimination. J Neurosci 24:8354-8365.

Gheusi G, Cremer H, McLean H, Chazal G, Vincent
JD, Lledo PM (2000) Importance of newly generated neurons in the adult olfactory bulb for odor discrimination. Proc Natl Acad Sci U S A 97:1823-1828.

Imayoshi I, Sakamoto M, Ohtsuka T, Takao K, Miyakawa T, Yamaguchi M, Mori K, Ikeda T, Itohara S, Kageyama R (2008) Roles of continuous neurogenesis in the structural and function integrity of the adult forebrain. Nat Neurosci 11:1153-1161.

Lagier S, Carleton A, Lledo PM (2004) Interplay between local GABAergic interneurons and relay neurons generates gamma oscillations in the rat olfactory bulb. J Neurosci 24:43824392.

Lazarini F, Mouthon MA, Gheusi G, de Chaumont F, Olivo-Marin JC, Lamarque S, Abrous DN, Boussin FD, Lledo PM (2009) Cellular and behavioral effects of cranial irradiation of the subventricular zone in adult mice. PLoS One 4:e7017.

Magavi SS, Mitchell BD, Szentirmai O, Carter BS, Macklis JD (2005) Adult-born and preexisting olfactory granule neurons undergo distinct experience-dependent modifications of their olfactory responses in vivo. J Neurosci 25:10729-10739.

Nissant A, Bardy C, Katagiri H, Murray K, Lledo PM (2009) Adult neurogenesis promotes synaptic plasticity in the olfactory bulb. Nat Neurosci 12:728-730.

Stopfer M, Bhagavan S, Smith BH, Laurent G (1997) Impaired odour discrimination on desynchronization of odour-encoding neural assemblies. Nature 390:70-74.

Wilson DA, Kadohisa M, Fletcher ML (2006) Cortical contributions to olfaction: plasticity and perception. Semin Cell Dev Biol 17:462470.

Yokoi M, Mori K, Nakanishi S (1995) Refinement of odor molecule tuning by dendrodendritic synaptic inhibition in the olfactory bulb. Proc Natl Acad Sci U S A 92:3371-3375. 